\title{
PERSONALITY TRAITS AND BEHAVIORAL PATTERNS ASSOCIATED WITH SYSTOLIC BLOOD PRESSURE LEVELS IN COLLEGE MALES
}

\author{
E. Harburg, Ph.D., S. Julius, M.D.*, N. F. McGinn, Ph.D., J. McLeod, Ph.D. \\ and S. W. HoObler, M.D.
}

The Department of Internal Medicine and The Program of Social Psychology, University of Michigan, Ann Arbor, Michigan

(Received 12 July 1963)

THE RELATIONSHIP between hypertension and certain psychological factors has long attracted scientific attention; however, only a few investigators have systematically studied the association between high systolic blood pressure and psychological characteristics in young subjects [1-6]. Published reports have mainly emphasized the psychological measurements; an analysis of blood pressure measurements has not received as much attention. In most studies, for example, the selection of subjects with 'high' and 'low' readings is based on a single blood pressure measurement. But, it is patent that young subjects with a single casual high or low systolic blood pressure reading do not remain in the same category when retested [7]. Better criteria have to be developed in order to describe the blood pressure patterns of these subjects, and before attempting to correlate pyschological and circulatory measurements. Furthermore, psychological measures might be improved by using objective devices which have been standardized on the population chosen for study. It is the aim of this paper to explore more precisely the relationship between psychological traits and various types of blood pressure indices in normal young college subjects.

\section{MATERIAL}

Five trained observers determined the blood pressure of 800 male students who were selected at random from a line waiting to undergo routine chest $X$-rays at the University of Michigan Health Service as a part of the registration procedure during the first week of college. Of these, 100 white subjects were chosen for subsequent study because their initial casual systolic reading was either over $140 \mathrm{~mm} \mathrm{Hg}$ or under $110 \mathrm{~mm} \mathrm{Hg}$. The average age of these students was 21.3 ranging from 17 to 25 years. Later by appointment 81 of these persons completed all phases of the blood pressure evaluation including the measurement of their own blood pressure three times daily for two days at their place of residence. On two subsequent occasions 74 of the 81 subjects were tested for certain personality and behavioral traits to be described later. These

*Present address: Department of Internal Medicine, University Medical School, Rebro, Zagreb, Yugoslavia. 
subjects were paid: they were told that the psychological testing was part of a psychosomatic research program, not necessarily related to their blood pressures. The physician did not know the results of the psychological tests. The scoring of all psychological measures was based on the subjects objective responses to scaled items and the test scores were processed mechanically.

\section{METHODS}

Circulatory measurements. To facilitate presentation, the following definitions are used.

1. Average casual blood pressure. This is the average of two casual systolic readings taken on separate occasions. The initial casual measurement was taken in the registration line and the second or office casual, was taken one month later by appointment at the time the student first entered the research physician's office. The average casual was a normally distributed variable due to a predictable regression toward the mean from the initial casual to the office casual [7].

2. Paired casual blood pressure. This refers to a subgroup of subjects whose systolic blood pressure remained at either high or low levels for both the initial casual and the office casual readings.

3. Usual blood pressure. This is an average of : (1) the median of 6 self-determined systolic readings taken in the subject's own living quarters; and (2) the average of 3 readings obtained after 20 minute bed rest in the physician's office. The median home blood pressure was highly correlated with the office resting measurement $(r=0.63$; $P<0.01)$.

4. Sustained blood pressure. This refers to a subgroup of subjects whose systolic blood pressure remained at either a high or a low level for both the average casual and the usual readings. These subjects therefore remained at relatively extreme but stable levels for 2 casual readings in 2 situations (registration line and office), on an average of 3 readings taken after rest at the office, and for the median of 6 readings taken at home.

In the following analysis, the words 'high' and 'low' refer to systolic blood pressure. In the case of 'high' readings, we do not mean to imply the presence of 'prehypertension.' While the initial selection of all subjects was based on 'high' (over $140 \mathrm{~mm}$ ) or 'low' (under $110 \mathrm{~mm}$ ) systolic readings, all diastolic readings were below $90 \mathrm{~mm} \mathrm{Hg}$. There were no significant differences among the diastolic blood pressure levels of these initially selected groups.

\section{PSYCHOLOGICAL MEASURES}

1. Cattell's $16 P F$ test (Form A). This test consists of 187 items, each with 3 response categories, e.g., True, Don't know, or False. It was designed to measure how the subject pictures himself as a person. The scales have been repeatedly factoranalyzed on college subjects, and only those items which contribute to factor stability have been retained. The significance of individual questions is not obvious to the subject. The detailed descriptions of factors referred to in this paper can be found in the 1957 edition of the 16 PF Handbook [8]. 
2. Mandler-Sarason Test Anxiety Questionnaire. Test anxiety was measured using a short form (Part II) of the Mandler-Sarason Test Anxiety Questionnaire. This 11item questionnaire asked for an indication of the degree of subjective symptoms experienced (sweaty palms, rapid heart beat, tension, etc.) before, during, and after taking examinations in school. A high score indicates the subject believes he experiences a high degree of most of the symptoms $[9,10]$.

3. Experimental yielding. During the first test session all subjects indicated their attitudes (on 7-point scales) to certain selected topics of interest, e.g., capital punishment, juvenile delinquency, etc. Subjects were later matched into pairs in which maximal disagreement existed on most of six topics. They were then called back one month later and were seated with their matched partner. They were told that they were matched by personality and would 'work well together.' They were requested to arrive through discussion at a compromise opinion, one which they might both support on each of the six topics. Before the discussion began each partner was asked to rate how much he liked his partner on a scale of intensity of liking. Then each subject was presented with a copy of his own and his partner's previously written opinion on the topics to be discussed. Three measures of yielding were obtained: (1) Anticipatory yielding: the number of scale point changes by which the subject privately believed he would modify his opinion to achieve the necessary compromise. (2) Compromise yielding: the number of scale points actually moved as a result of the discussion and done overtly during the discussion with the partner's knowledge. (3) Private yielding: the number of scale points the subject moved from his attitudes as privately expressed in the first test situation to his attitudes which he privately expressed after the discussion. The subject's scores in (1) and (3) are independent of his partner's scores; and differences were tested by the Mann-Whitney Test. Scores on (2) were reciprocal and were tested by the Wilcoxon Signed-Ranks Test. For a more complete description of these procedures and measures, see MCLEOD [11].

\section{RESULTS}

\section{Classification of subjects by blood pressure}

Table 1, which summarizes the major findings relating psychological self-reports and blood pressure, requires some explanation. The data are analyzed according to different measures of blood pressure. Correlation statistics for average casual and usual blood pressure levels were obtained in order to test for relationships covering the full range of these normally distributed scores. For the paired casual, usual and sustained measures, a second analysis was made by frequency tables using only the extreme ends of the distribution, and tested by Fisher's Exact Test. It should be noted that any relationship between casual and usual blood pressure measures and psychological traits gains added import, since the readings by which the classification of a usual level is obtained are different from those used in determining the casual levels.

\section{Comparison of blood pressure patterns with psychological traits: 16 PF test}

The first two columns in Table 1 show the results of correlating the average casual and usual systolic blood pressures with the 16 PF Questionnaire for the full group of 


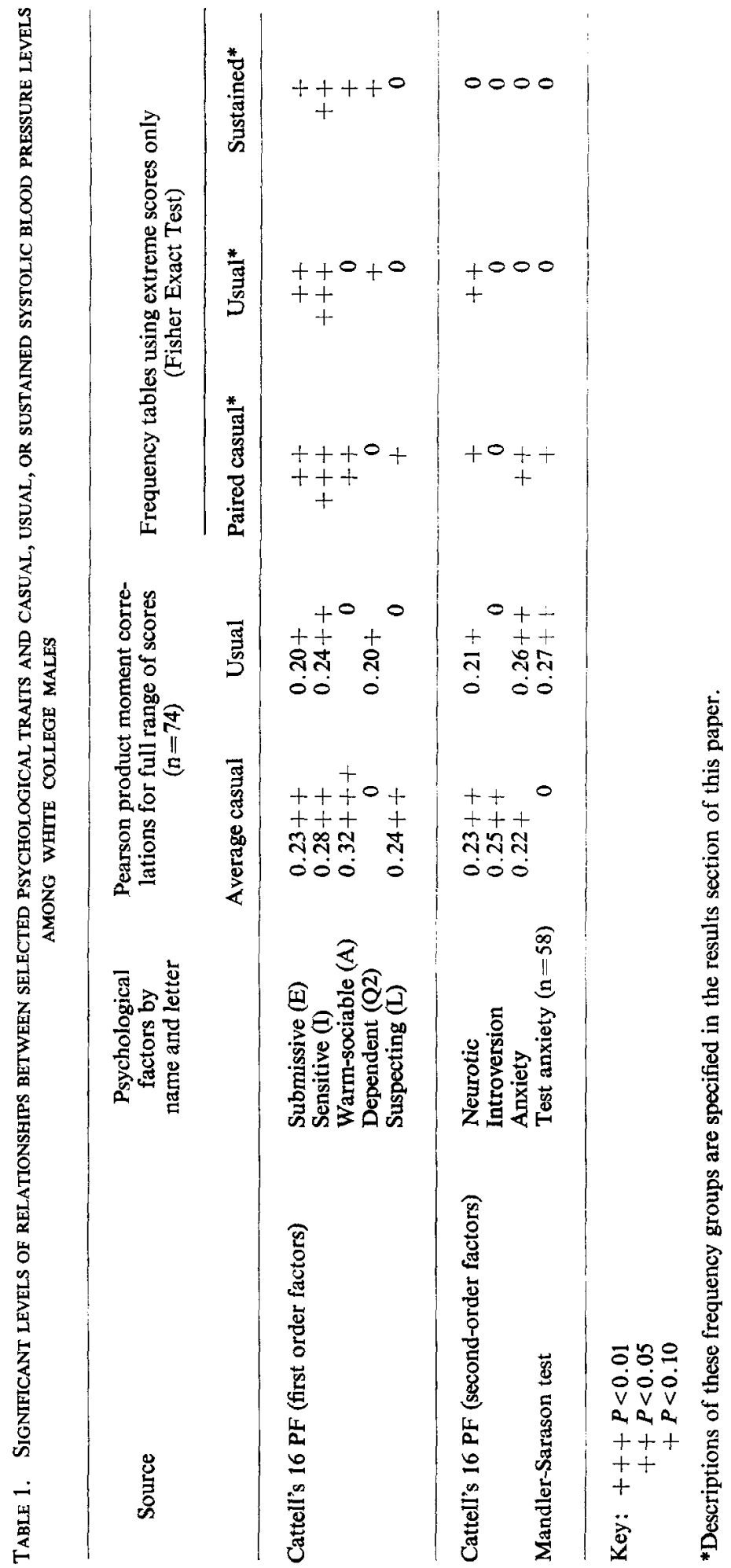


subjects ( $n=74)$. In the last 3 columns results are presented first when the number of cases was reduced to 49 by requiring that both (not the average) of the 2 casual readings taken should exceed $140 \mathrm{~mm} \mathrm{Hg}$ or be below $110 \mathrm{~mm}$ systolic pressure. Of these 49 , there were 21 who fell into the 'paired casual high,' and 28 into the 'paired casual low' categories. Similarly the number of cases classified by 'usual' systolic pressure was reduced to 34 when extremes were selected. Of these, 18 were defined as 'usual low' (under $113 \mathrm{~mm}$ ) and 16 as 'usual high' (over $131 \mathrm{~mm}$ ). Finally a sustained 'high' ( $\mathrm{n}=$ $11)$ and a sustained 'low' group $(n=15)$ were selected from persons in whom the initial and the office casuals and the usual blood pressures were all either greater than $131 \mathrm{~mm}$ or less than $113 \mathrm{~mm}$ respectively.

Cattell's 16 PF questionnaire describes 19 psychological categories: 16 first-order factors, and 3 second-order factors which include weighted combinations of the first order factors. All 19 categories were correlated with both casual and usual systolic blood pressure classifications. Of the 38 possible relationships, 12 traits showed significant correlations above the 0.10 level, of which 9 exceeded the 0.05 level (Table 1 , columns 1 and 2). All of these correlations were modest; none exceeded 0.32 . Both casual and usual systolic blood pressure levels showed some significant correlation with 2 first-order traits (submissiveness, sensitivity) and 2 second-order characteristics (neuroticism, anxiety). The qualities 'warm-sociable' and 'introverted' were highly correlated only with the average casual blood pressure. When groups were re-examined according to the extremes of these categories and were tested for significance by the Fisher Exact Test somewhat similar conclusions were reached. There were significant associations between the 'high' categories and the subject's characterization as 'submissive,' 'sensitive' and 'neurotic.' These and other less significant associations are presented in the last 3 columns of Table 1 .

\section{Measures of anxiety}

Two measures of anxiety were used in this study, the second-order factor of anxiety in the $16 \mathrm{PF}$ questionnaire, which measures a general anxiety, and the MandlerSarason Test, which measures a specific type of anxiety, namely recognition of physiological symptoms by the subject when taking school examinations. The two anxiety measures were not significantly correlated in this study group. Table 1 shows that persons extremely high on the 'paired casuals' (high on both the registration line and the first reading in the office) also tended to be high on both measures of anxiety. Nevertheless while higher 'usual' systolic readings were correlated with both measures of anxiety, analysis of the extreme groups showed only the 'high paired casuals' as being significantly more anxious. The same tendency existed for the other extreme groups but was not statistically significant.

\section{Experimental yielding}

Twelve persons with 'high casual' and 12 with 'low casual' blood pressure patterns were matched post hoc by this method.* Figure 1 shows that the 'casual high' subjects

\footnotetext{
*The term 'casual' here refers to the single systolic reading taken by the physician when the subject first entered the office for an hour exam. We would have preferred to use the average of the two casual readings, but too few of the 49 subjects who had extreme high or low average casual readings became matched as partners in this experiment. This occurred because the psychological tests were given separately, and the initial matching into partners was done solely on the basis of differences in attitudes, with no knowledge of blood pressure results. (There were no relationships between attitudes being discussed and blood pressure levels.)
} 


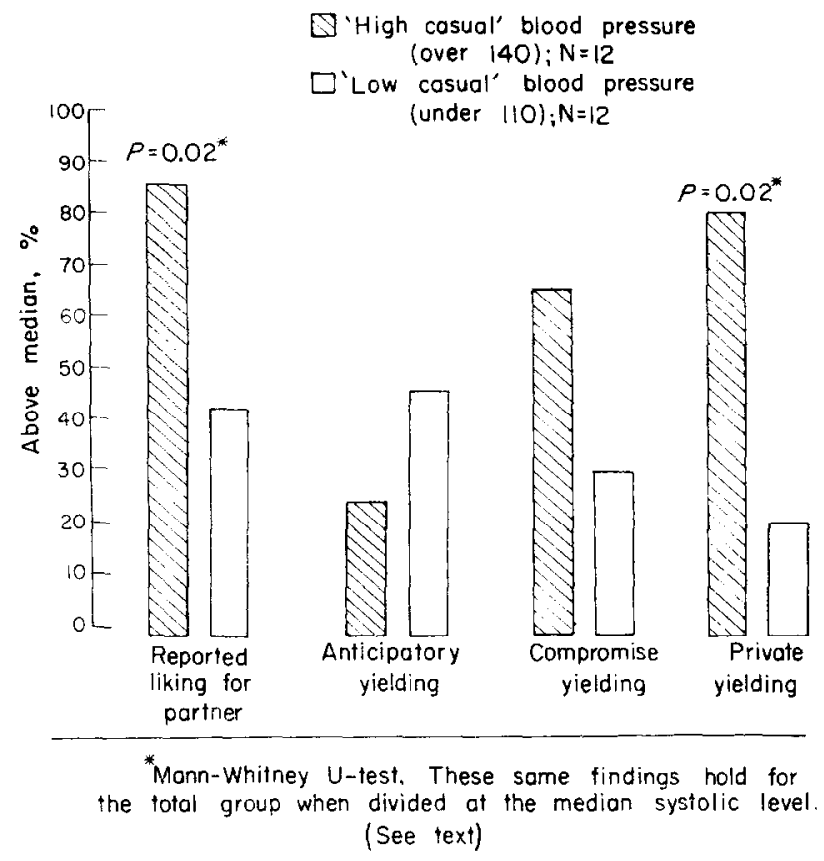

FIG. 1. Relations between liking for partner, yielding and office casual systolic blood pressure levels.

reported liking their 'low casual' partners more intensely than the total group average before the discussion and after only a 5 min acquaintance. They then estimated they did not anticipate yielding their opinion, but in fact, did yield more in the argument; and afterwards privately changed their opinion considerably toward agreement with their partner's position. This public and private yielding seems similar to the picture of 'submissiveness' obtained by the $16 \mathrm{PF}$ test for those persons with 'high average casual' blood pressure. The greater intensity of liking also seems consistent with self-reports of having a 'warm-sociable' make-up described by this larger group (Table 1).

The findings in Fig. 1 were also found using the entire group of those 62 subjects who participated in this experiment. By dividing the distribution of their single office casual systolic reading at the median, two groups are obtained, the 'high systolic' ( $\mathrm{n}=28,126 \mathrm{~mm} \mathrm{Hg}$ and above) and 'low systolic' ( $\mathrm{n}=34,124 \mathrm{~mm} \mathrm{Hg}$ and below). Before the discussion, 82 per cent of these 'highs' reported intensities of liking above the median of the distribution, while only 50 per cent of the 'lows' were over the median. (Mann-Whitney U-test: $P=0.003$ ). Similarly 75 per cent of the highs were above the median for privately yielding after the discussion compared with 29 per cent of the 'lows' (Mann-Whitney U-test: $P=0.0007$ ).

\section{Influence of body weight on results of psychological testing}

In this study, subjects with a high 'average casual' blood pressure tended to be predominantly overweight. It was therefore necessary to examine whether the psychological traits which were correlated with a high casual blood pressure level were also characteristic of overweight. This question is examined in Table 2 where it is 
shown that overweight is associated with a personality pattern of its own, quite independently from the factors correlated with a 'high average casual' or a 'high usual' systolic blood pressure. This occurs despite the significant correlation between overweight and a high average casual blood pressure $(r=0.55 ; P<0.01)$ or between overweight and a high usual reading $(r=0.52 ; P<0.01)$.

Table 2. Significant levels of Personaltiy tratts (CATtell's 16 PF) Correlated with average CASUAL AND USUAL SYSTOLIC BLOOD PRESSURE AND OVERWEIGHT $(n=74)$

\begin{tabular}{lccc}
\hline & $\begin{array}{c}\text { Average } \\
\text { casual }\end{array}$ & Usual & Overweight* \\
\hline Warm-sociable & $0.32+++$ & 0 & 0 \\
Suspecting & $0.24++$ & 0 & 0 \\
Introverted $\dagger$ & $0.25++$ & 0 & 0 \\
Submissive & $0.23++$ & $0.20+$ & 0 \\
Sensitive & $0.28++$ & $0.24++$ & 0 \\
Neurotic $\dagger$ & $0.23++$ & $0.21+$ & 0 \\
Dependent & 0 & $0.20+$ & $0.21+$ \\
Test anxiety & 0 & $0.27++$ & $0.20+$ \\
Confident & 0 & 0 & $0.23++$ \\
\hline
\end{tabular}

Key: $\begin{aligned}+ & +P \\ + & P<0.01 \\ & +P<0.05 \\ & \end{aligned}$

*According to Metropolitan Life Insurance Standards.

†These are second-order factors which may include the other first-order factors shown.

$\neq n-58$ (Mandler-Sarason test).

\section{DISCUSSION}

Any group of young male subjccts who on one casual reading shows a 'high' systolic blood pressure will subsequently divide into three subgroups: (1) some will show normal readings on further re-examination; (2) some will have transient rises of blood pressure only after appropriate stimuli, but will again at times fall to normal ('variable high'); and (3) there will be a subgroup exhibiting a mild, but sustained, high reading on further casual readings including home readings ('usual or sustained high').

This discussion will focus on the third group. Their psychological features were fairly distinctive in our selected student population. They reported themselves to be predominantly 'sensitive,' as opposed to being 'hard-headed', more prone to 'submissiveness' than 'dominance' in minor social conflicts; more 'warm' and 'dependent' towards other people, yet caught in 'neurotic' conflicts. Simply stated, this self-image may portray a basic conflict of wanting to assert oneself, and yet being unable to do so.

The objection might be raised that the psychological distinctions found in our group of young college males were related to overweight rather than to higher blood pressure levels since overweight and higher systolic blood pressure levels were significantly correlated in ours as in other population studies. However, the psychological features accompanying the two conditions seem quite different (Table 2). Instead of being 'submissive' and 'sensitive.' the overweight person describes himself as more 'confident' in life; physically, he appears active and energetic.

When our findings are compared with other research in this field, certain similarities seem to be present. Being 'sensitive,' apparently however measured, appears to be a 
leading trait of young subjects with elevated blood pressure, since in one way or another it is mentioned by several authors who have studied young 'hypertensive' subjects $[1,3,5,6]$. In AYMAN's study of 'young hypertensives' [1] for example, 66 per cent of the high blood pressure group (mostly young males, over $140 \mathrm{~mm}$ systolic) described themselves as persons whose feelings are usually hurt and who are unusually sensitive. This compares to only 18 per cent of the controls who agreed to this self-description. The 'submissiveness' factor which was so typical of our material was also the same trait found by HAMILTON among his college students with higher systolic pressures [3]; his subjects had also rated themselves on a standardized form (Allport scale of ascendance-submission). The 40 'prehypertensive' college females described by HARRIS et al. [4] also rated themselves significantly more 'submissive' on the Gough Adjective Test than did a control group of normals.

Our subjects also tended toward higher self ratings on items describing 'neuroticism.' This seems similar to HARRIS' report [5] of teen-age, normotensive males who were clinically described as 'timid, moody, dependent, and awkward in social situations.' THACKER [7], who took measures of blood pressure on college males over four separate occasions and also isolated a group of 'sustained' highs, reports 43 per cent of this high group as 'ncrvous or excitable' compared to 12 per cent of the 'sustained' lows. Our subjects also reported themselves as being 'warm' and 'dependent' which when combined with the traits of 'sensitivity' and 'submissiveness' also suggests neurotic conflicts.

Questionnaire responses may, of course, differ from behavior in face-to-face situations. Nevertheless the above traits seem to appear in behavior during psychodramas as reported by KaLIS et al. [6]. These authors suggest that the pattern of such behaviors may be called 'inappropriate assertiveness.' It is not that the high blood pressure females whom they studied were lacking in 'assertiveness,' but that in defined types of social situations, this assertive behavior was either too much or too little or awkwardly done.

Our own experimental findings on 'yielding' behavior were confined to those subjects who were high or low on a single reading of systolic pressure taken when the subject first entered the physician's office for an hour examination of their blood pressure. Using a small group of persons who were extreme on this office casual reading, the 'highs' showed behavior of privately yielding in a face-to-face argument with a partner who had an extreme 'low' reading. The 'highs' also reported an above average liking for their new acquaintance. These same findings held for the total group of subjects when systolic blood pressure was divided at the median level. It has been shown by N CLEOD [11] in two other populations of college students (male and female) that higher expressed liking for the new acquantance in identical experiments also led to varying patterns of increased yielding in the argument. It is of interest that SHAPIRO [12] found more of his adult hypertensive patients rating the doctor as more 'friendly' after receiving noxious stimuli from him than did the 'normal' controls.

Other evidence suggests that the self-described traits and the behavior of our young male normotensives seem to resemble those alleged to characterize adult hypertensive subjects [13]. Either the traits simply accompany a tendency to high normal blood pressures or they may play a role in the genesis of hypertension. Prospective studies in which adequate physiological and psychological measures are obtained at early, middle and later life periods may best serve to examine this problem. 


\section{SUMMARY}

1. Seventy-four young white male college students (out of an original pool of 800 examined) were selected for having high or low systolic readings taken on a registration line. These students were then classified according to their paired casual, usual, and sustained levels of systolic blood pressure. Of 21 persons with a high paired casual systolic blood pressure (two independent determinations in excess of $140 \mathrm{~mm} \mathrm{Hg}$ ), 16 were also characterized as belonging to a 'usual high' group (blood pressure in excess of $131 \mathrm{~mm}$ on resting and repeated home readings). A 'sustained' high blood pressure group $(\mathrm{n}=11)$ was further obtained by selecting those who were 'high' on their paired casual and their 'usual' blood pressure levels. These blood pressure patterns were then related with self ratings on the Cattell $16 \mathrm{PF}$ questionnaire.

2. A consistent elevation to the upper range of normal in the systolic blood pressure of these college males was associated with 'submissiveness' and 'sensitivity' as defined by Cattell's 16 PF questionnaire. Subjects with 'high paired casual' systolic blood pressures described themselves as motivated to obtain social contacts, but in a 'sensitive' and 'anxious' manner.

3. Subjects who were later selected for having a single high systolic blood pressure reading taken on first entering the physician's office (their second casual reading) tended more frequently to yield in an argument and then afterwards to change their private opinions toward agreement with partners who had an initially low systolic reading.

4. Whereas obesity was highly correlated with higher systolic levels, the psychological correlates of obesity were different from those related to elevated 'casual' or 'sustained' blood pressure. Obese subjects in this population appeared to be physically active, and more confident, though somewhat anxious under the stress of school examinations.

Acknowledgements - This work was supported by Grant No. H 2578, U.S. Department of Health, Education and Welfare.

We wish to thank Dr. MoRLey Becketr of the University of Michigan Student Health Service for his generous assistance to us in this research.

\section{REFERENCES}

1. Ayman, D.: The personality of patients with essential arterial hypertension, Amer. J. med. Sci. $186,213,1933$.

2. Armstrono, H. G.: The blood pressure and pulse rate as an index of emotional instability, Amer. J. med. Sci. 195, 211, 1938.

3. Hamiton, J. A.: Psychophysiology of blood pressure, Psychosom. Med. 4, 125, 1942.

4. Harris, R., Sokolow, M., Carpenter, L., Friedman, M. and Hunt, S.: Response to psychologic stress in persons who are potentially hypertensive, Circulation 7, 874, 1953.

5. Harris, R. E.: Some observations on blood pressure in children, 26th Rep. Ross Pediatric Res. Conf. pp. 49-54, 1958.

6. Kalis, B. L., Harris, R. E., Sokolow, M. and Carpenter, L. G., Jr.: Response to psychological stress in patients with essential hypertension, Amer. Heart. J. 53, 572, 1957.

7. THACKER, E. A.: A comparative study of normal and abnormal blood pressures among university students, including the cold pressor test, Amer. Heart J. 20, 89, 1940.

8. Institute for Personality and Ability Testing: Handbook for the I6 P.F. Test. IPAT, Champaign, Illinois, 1957.

9. MANDleR, G. and Sarason, S. B.: A study of anxiety and learning, J. abnorm. soc. Psychol. 47, $166,1952$. 
10. Mandler, G. and Sarason, S. B.: The effect of differential instructions on anxiety and learning, J. abnorm. soc. Psychol. 47, 561, 1952.

11. MCLeOD, J. M.: Yielding as a response to cognitive imbalance. Unpublished Ph.D. thesis. University of Michigan, 1962.

12. Shapiro, A. P.: An experimental study of comparative responses of blood pressure to different noxious stimuli, J. chron. Dis. 13, 293, 1961.

13. Gressel, G. C., Shobe, F. O., Saslow, G., DuBois, P. J. and Schroeder, H. A.: Personality factors in essential hypertension, J. Amer. med. Ass. 140, 265, 1949. 